Supplement of The Cryosphere, 13, 3023-3043, 2019

https://doi.org/10.5194/tc-13-3023-2019-supplement

(c) Author(s) 2019. This work is distributed under

the Creative Commons Attribution 4.0 License.

(c) (1)

Supplement of

Effect of prescribed sea surface conditions on the modern and future Antarctic surface climate simulated by the ARPEGE atmosphere general circulation model

Julien Beaumet et al.

Correspondence to: Julien Beaumet (julien.beaumet@univ-grenoble-alpes.fr)

The copyright of individual parts of the supplement might differ from the CC BY 4.0 License. 
Table S1. Annual and seasonal Southern Hemisphere mean historical Sea Ice Extent (SIE, $10^{6} \mathrm{~km}^{2}$ ) in observations, NorESM1-M and MIROC-ESM.

\begin{tabular}{|c|c|c|c|c|c|}
\hline & Year & DJF & MAM & JJA & SON \\
\hline Observations & 9.6 & 4.4 & 5.6 & 13.5 & 14.7 \\
\hline NorESM1-M & 9.8 & 4.8 & 6.6 & 14.0 & 15.4 \\
\hline MIROC-ESM & 8.9 & 3.1 & 4.0 & 13.3 & 15.3 \\
\hline
\end{tabular}

Table S2. Annual and seasonal Southern Hemisphere mean projected Sea Ice Extent and absolute change with respect to historical climate $\left(10^{6} \mathrm{~km}^{2}\right)$ in NorESM-1M and MIROC-ESM RCP8.5 projection and in corresponding bias-corrected SSC.

\begin{tabular}{|c|c|c|c|c|c|}
\hline & Year & DJF & MAM & JJA & SON \\
\hline NOR-21 & 8.2 & 4.0 & 5.1 & 11.7 & 13.6 \\
\hline Change $\left(10^{6} \mathrm{~km}^{2}\right)$ & -1.6 & -0.8 & -1.5 & -2.3 & -1.8 \\
\hline NOR-21-OC & 7.9 & 3.5 & 4.2 & 11.1 & 12.7 \\
\hline Change $\left(10^{6} \mathrm{~km}^{2}\right)$ & -1.6 & -0.8 & -1.5 & -2.3 & -1.8 \\
\hline MIR-21 & 4.2 & 0.9 & 1.2 & 6.8 & 8.2 \\
\hline Change $\left(10^{6} \mathrm{~km}^{2}\right)$ & -4.7 & -2.2 & -2.8 & -6.5 & -7.2 \\
\hline MIR-21-OC & 4.2 & 1.0 & 1.5 & 6.8 & 7.6 \\
\hline Change $\left(10^{6} \mathrm{~km}^{2}\right)$ & -5.3 & -3.4 & -4.1 & -6.7 & -7.1 \\
\hline
\end{tabular}

\section{Sea Surface Conditions}

In this section, we present the historical bias in SSC in MIROC-ESM and NorESM1-M (Fig. S1a, S1b) used to drive ARPEGE model as well as the differences between ${ }_{5} \mathrm{SSC}$ in RCP8.5 projection in these model and their biascorrection (Fig. S1c, S1d). The skills of the bias-correction method for SSC can be appreciated as the similarity between differences in future and present SST is striking. For SIC, the pattern of the model bias in historical climates can easily 10 be identified in the differences between original and biascorrected SSC (Fig. S1), but because there is a decrease of SIE, these patterns are shifted poleward. Yearly and seasonal South Hemisphere SIE in MIROC-ESM, NorESM1$\mathrm{M}$ and observations (Table S1) and in the two AOGCMs 15 original and bias-corrected RCP8.5 projection are presented in Table S2. Statistics show that the efficiency of the biascorrection methods to reproduce the climate change signal in hemispheric SIE from the coupled model is confirmed. In Fig. S2, SST historical bias for the two coupled models for ${ }_{20}$ each season in the southern hemisphere are displayed in order to support the discussion on how the atmospheric model has responded to the same SST biases or perturbations in present and future climate (Sec. 4.2.2).

In Table S2, the climate change signals in SIE in projec25 tions from MIROC-ESM and NorESM1-M can be evaluated, with the decrease in sea ice being three times importanter in MIROC-ESM projection. It can also be noted that both AOGCM hemispheric SIE are relatively close to the observations. Only an underestimate of about $20 \%$ in summer and so autumn SIE in MIROC-ESM can be mentioned.

\section{Near-surface temperatures}

In this section, we present additional material for the evaluation of near-surface temperatures $\left(\mathrm{T}_{2 m}\right)$ as simulated by ARPEGE AGCM and for the assessment of the effect of prescribed SSC.

\subsection{Model evaluation}

The difference between $\mathrm{T}_{2 m}$ from the ARP-AMIP simulation and those from the MET READER data base and corresponding evaluation statistics can be seen in Table S3. The location of the weather station can be seen on the right panel 40 of Fig. 4.

\subsection{Effects of prescribed SSC}

The effect of introducing biased SSC on the modelling of Antarctic $\mathrm{T}_{2 m}$ with ARPEGE AGCM is presented in Fig. S3. 45 For ARP-NOR-20 (Fig. S3a), the introduction of biased SSC increase the warm bias on the East Antarctic Plateau (EAP) with respect to MAR and weather stations already present in ARP-AMIP (Fig. 4). The same statement can be made for the winter cold bias over the Peninsula. In summer, there are relatively few differences in the skills of the latter two simulations, which is consistent with similar errors on large-scale atmospheric circulation (Fig. 2).

For ARP-MIR-20 (Fig. S3b), the cold bias over the Peninsula is also larger than ARP-AMIP for both seasons. The winter 55 warm bias over the EAP is similar than in ARP-AMIP. In summer, the general tendency of ARP-MIR-20 to be cooler than ARP-AMIP over the continent leads to a decrease of the warm bias with respect to MAR over the margins of the EAIS and WAIS on one hand, but increase the cold bias on the EAP on the other hand, which can be seen in the differences with MAR and weather stations.

\subsection{Ice Shelves}

In this section, we further investigate the causes of the large discrepancies between ARPEGE and MAR over ice shelves and try to evaluate which part these discrepancies are actually due to the systematic biases of each model. Over the large ice shelves (Ronne-Filchner and Ross) the ARP-AMIP simulation is systematically 7 to $10 \mathrm{~K}$ (up to $12 \mathrm{~K}$ over the center of Ross) warmer than MAR in winter, while in sum- 70 mer, it is $5-7 \mathrm{~K}$ cooler (Fig. 4). While very few in-situ temperature records long enough to evaluate a freely evolving climate model such as ARPEGE is currently available for these areas, the MAR-ERA-I simulation has been evaluated against automatic weather station from the READER data 75 base (Agosta, 2018). Over the Ross Ice Shelf, MAR shows an average systematic bias of $-2.8 \mathrm{~K}$ with biases larger than $5 \mathrm{~K}$ for the coolest stations (center of the ice shelf). This suggests that about $1 / 3$ of the MAR-ARPEGE discrepancy 

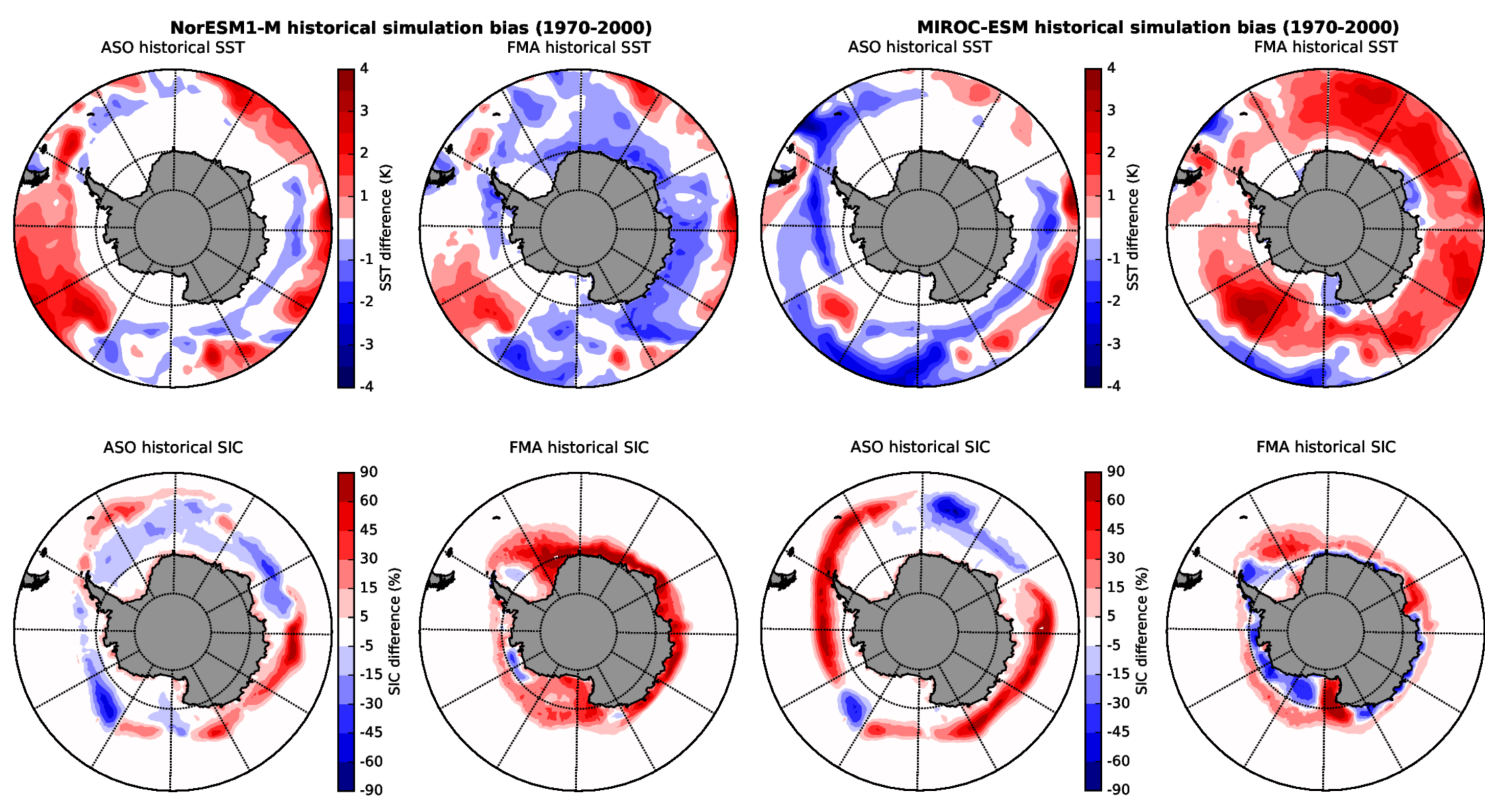

a) NorESM1-M historical
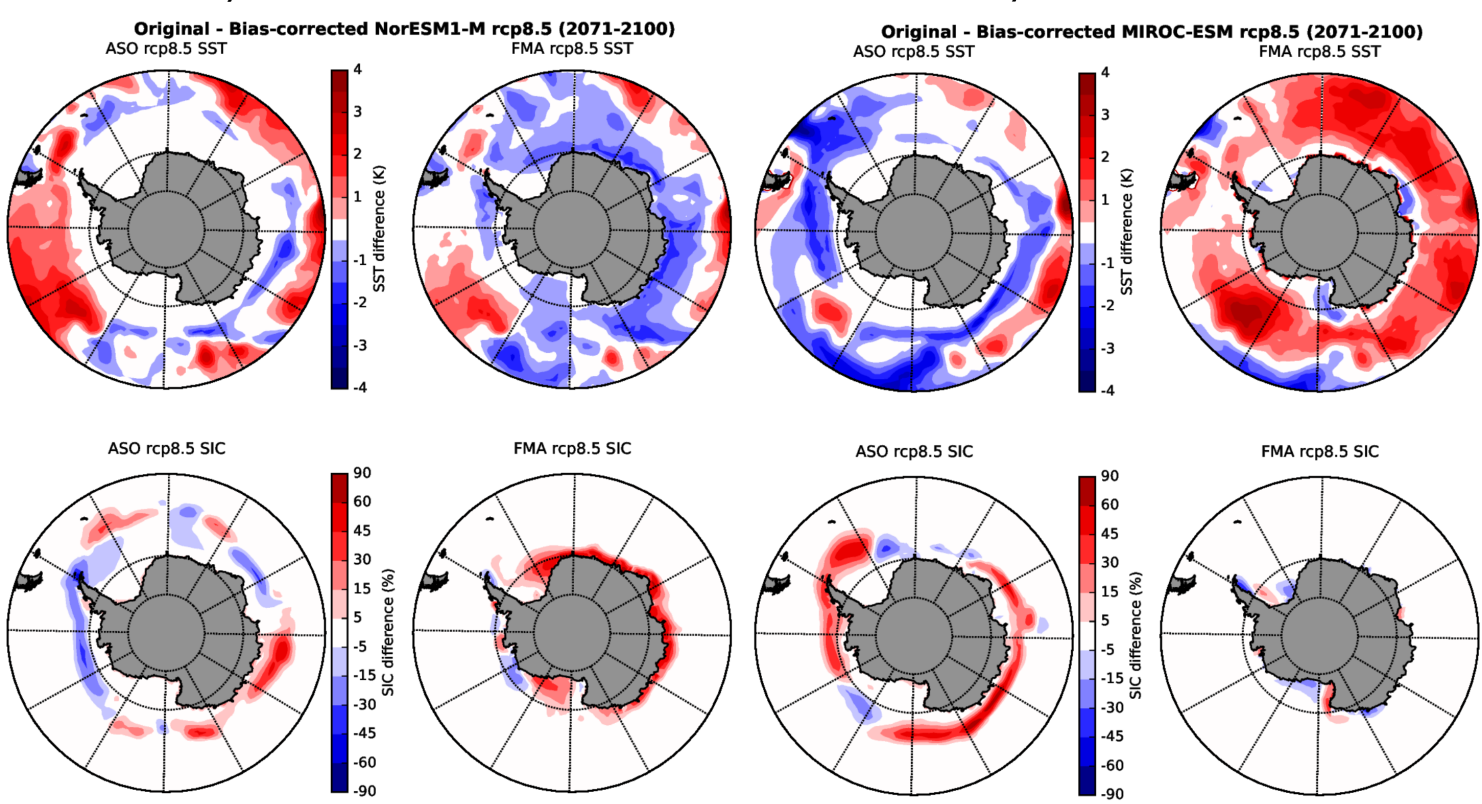

c) NorESM1-M RCP8.5

d) MIROC-ESM RCP8.5

Figure S1. Bias or difference with bias-corrected reference in SST (top) and SIC (bottom) for late winter, (ASO : August, September, October, left) and late summer (FMA :February, March, April, right) for NorESM1-M (a) and MIROC-ESM $(b)$ and corresponding difference for their RCP 8.5 projections (resp. $c$ and $d$ ) for late $21^{\text {st }}$ century. 

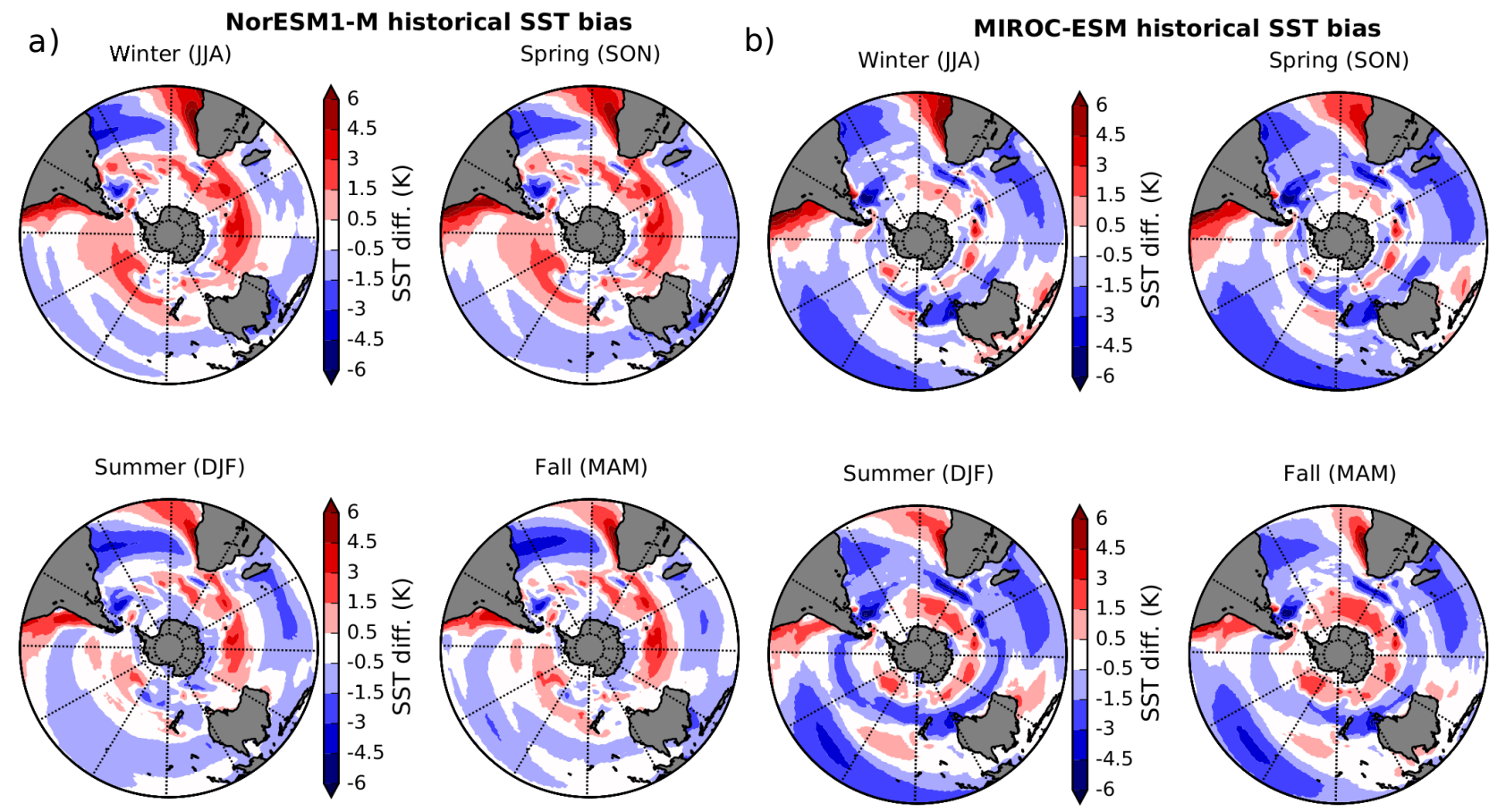

Figure S2. Seasonal historical bias in SST in the Southern hemisphere from NorESM1-M $(a)$ and MIROC-ESM $(b)$.

over large ice shelves in winter seems to actually comes from a MAR cold bias over these areas. This can also be seen over smaller ice shelves of the Dronning Maud Land area where ARPEGE is 5-7 $\mathrm{K}$ warmer in winter when compared 5 to MAR, while ARPEGE biases with respect to Halley and Neumayer weather station located over ice shelves of this area are respectively only +1.2 and $+0.9 \mathrm{~K}$ (Table S3). The evaluation in Agosta (2018) shows that MAR also has a $\sim 3$ $\mathrm{K}$ cold bias over ice shelves in summer, which suggests that 10 ARPEGE cold bias might be even larger during this season. This analysis seems to be confirmed in the comparison between ARP-AMIP and RACMO2 (Fig. S9) where ARPEGE "warm bias" over ice shelves is reduced over most of the Ross Ice Shelf $(<5 \mathrm{~K})$ and almost completely disappears 15 over Ronne-Filchner while ARPEGE "cold bias" over these areas in summer is more striking.

In the following, we examine differences between MARERA-I and ARP-AMIP for different components of the surface energy balance (latent heat flux, sensible heat flux, ${ }_{20}$ downward long-wave radiation), albedo and near-surface temperature inversion. Unlike what has been done for nearsurface temperature, wind speed, surface pressure and SMB, the MAR-ERA-I simulation has not been rigorously evaluated against observational data sets for these variables. As a ${ }_{25}$ consequence, here more than anywhere else, these comparisons are meant to help in understanding model-model differences rather than being an indirect evaluation of ARPEGE model.

In the version of ARPEGE used, ice shelves were not consid- ered as land in the land surface model. To solve this issue, we 30 have prescribed the sea-ice concentration to be $100 \%$ and the sea ice thickness to be 40 meters in order to simulate realistic heat fluxes at the surface. These modifications allowed to completely shut down latent heat fluxes from the surface (Fig. S4) and to have negative sensible heat fluxes (heat transfert from the atmosphere to surface, Fig.S5) in winter as expected, and in agreement with the fluxes modelled in MAR simulation. Thanks to the accumulation of snow on top of sea ice accounted for in GELATO, the effective albedo (SWU/SWD, Fig. S8) over ice shelves in ARPEGE compares reasonably well with MAR. This statement is also valid for most of the ice sheet. The structure of the nearsurface inversion has been investigated as another possible explanation for discrepancies between MAR and ARPEGE. To do so, we represent the difference between surface tem- 45 perature $\left(\mathrm{T}_{s}\right)$ and the temperatures at 20 metres $\left(\mathrm{T}_{20 m}\right)$ in both model and the corresponding difference (Fig. S7). Over large ice shelves, the seasonality of the differences (weaker near-surface inversion in ARPEGE in winter, and larger in summer) is consistent with the differences in near-surface 50 temperatures between the two model along the seasons. This statement is also valid for the very top of the high Antarctic Plateau where ARPEGE tends to be too warm (with respect to MAR and observations) in winter and slightly too cold in summer. This suggests that ARPEGE underestimates the strength of near-surface temperature inversion due to the formation of very stable boundary layer in winter as many climate models do (King et al., 2001; Bazile et al., 2014, e.g.,). 
a) ARP-NOR-20

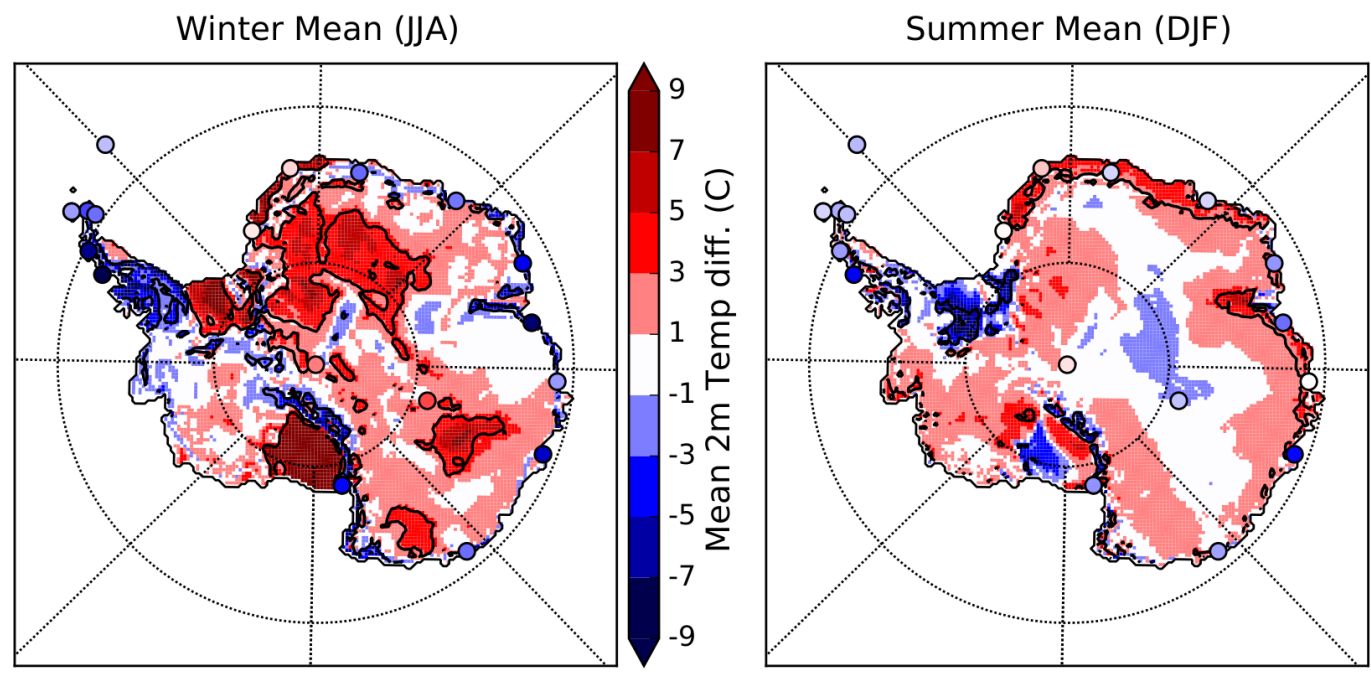

b) ARP-MIR-20
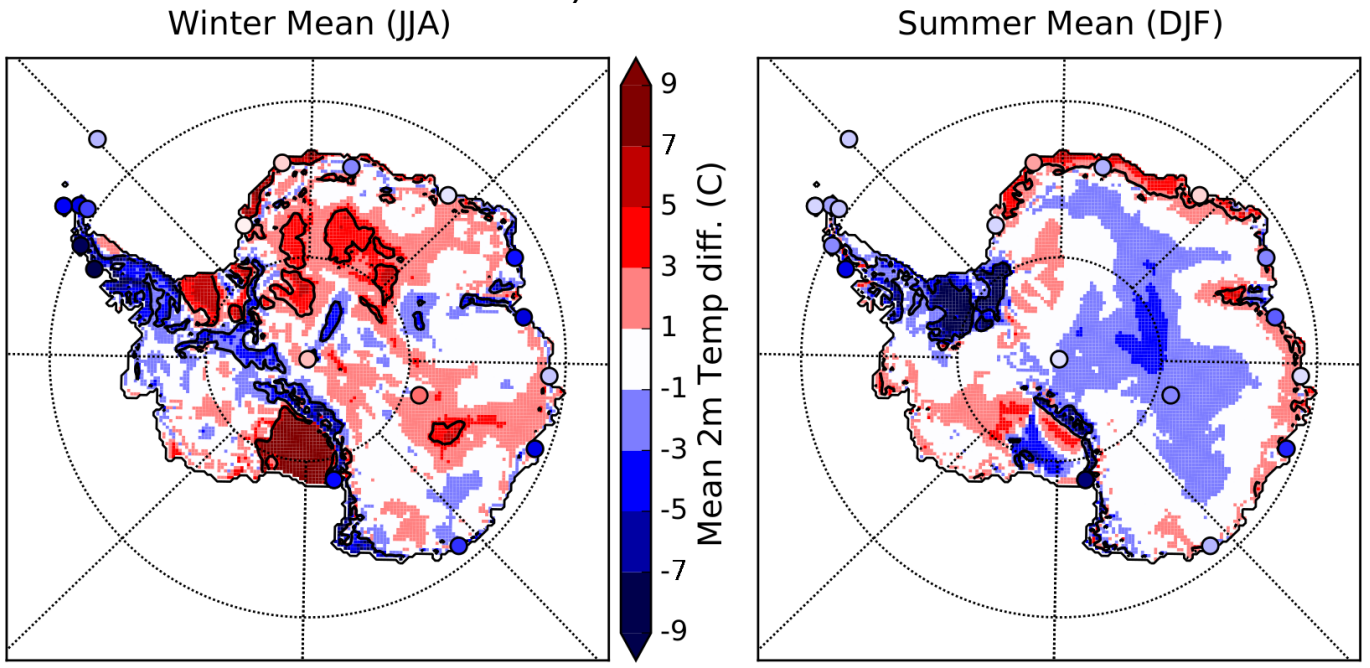

Figure S3. T $2 m$ differences between ARP-NOR-20 $(a)$ and ARP-MIR-20 $(b)$ and MAR-ERA-I simulations in winter (JJA, left) and summer (DJF, right) for the reference period 1981-2010. Circles are $\mathrm{T}_{2 m}$ differences between ARP-AMIP and weather stations from the READER data base. Black contour lines represent areas where $|A R P E G E-M A R|>1 . M A R \sigma$. 
Table S3. Error on READER weather station $\mathrm{T}_{2 m}$ (in K) in the ARP-AMIP simulation for the reference period 1981-2010. Errors significant at $\mathrm{p}=0.05$ are presented in bold.

\begin{tabular}{|c|c|c|c|c|}
\hline Stations & DJF & MAM & JJA & SON \\
\hline \multicolumn{5}{|l|}{ EAP } \\
\hline Amundsen Scott & 0.5 & 2.4 & 1.1 & 0.9 \\
\hline Vostok & -1.5 & 3.2 & 3.2 & 1.9 \\
\hline Mean error & -0.5 & 2.8 & 2.1 & 1.4 \\
\hline RMSE & 1.1 & 2.8 & 2.4 & 1.5 \\
\hline \multicolumn{5}{|l|}{ Coastal EA } \\
\hline Casey & -4.0 & -5.7 & -6.9 & -5.4 \\
\hline Davis & -1.6 & -4.2 & -6.0 & -3.3 \\
\hline Dumont Durville & -0.5 & -2.8 & -4.1 & -2.2 \\
\hline Mawson & -2.2 & -4.3 & -5.7 & 4.3 \\
\hline McMurdo & -7.1 & -6.5 & -8.1 & -8.4 \\
\hline Mirny & -1.2 & -2.2 & -3.0 & -2.0 \\
\hline Novolazarevskaya & 2.5 & 0.6 & -1.0 & 0.6 \\
\hline Scott Base & -5.0 & -3.1 & -4.6 & -5.0 \\
\hline Syowa & -0.2 & -0.6 & -1.5 & 0.0 \\
\hline Mean error & -2.2 & -3.3 & -4.5 & -3.3 \\
\hline$R M S E$ & 3.5 & 3.9 & 5.1 & 4.3 \\
\hline \multicolumn{5}{|l|}{ Ice shelves } \\
\hline Halley & 1.3 & 2.5 & 1.2 & 0.9 \\
\hline Neumayer & 2.2 & 1.2 & 0.9 & 1.4 \\
\hline Mean error & 1.7 & 1.8 & 1.1 & 1.2 \\
\hline RMSE & 1.8 & 1.9 & 1.1 & 1.2 \\
\hline \multicolumn{5}{|l|}{ Peninsula } \\
\hline Bellingshausen & -1.0 & -0.4 & -0.2 & -0.1 \\
\hline Esperanza & -1.1 & 0.5 & -1.3 & -0.9 \\
\hline Faraday & -2.7 & -4.7 & -5.7 & -3.7 \\
\hline Marambio & -1.9 & 1.0 & -1.3 & -1.6 \\
\hline Marsh & -0.8 & -0.4 & -0.3 & -0.0 \\
\hline Orcadas & -1.1 & -0.0 & 0.6 & -0.8 \\
\hline Rothera & -5.6 & -7.9 & -8.7 & -6.1 \\
\hline Mean error & -2.0 & -1.7 & -2.4 & -1.9 \\
\hline$R M S E$ & 2.6 & 3.5 & 4.0 & 2.8 \\
\hline \multicolumn{5}{|l|}{ Southern Ocean } \\
\hline Gough & -1.0 & -0.3 & 0.0 & -0.8 \\
\hline Macquarie & -0.7 & -0.4 & 0.2 & -0.5 \\
\hline Marion & -1.2 & -0.4 & -0.1 & -0.7 \\
\hline Mean error & -1.0 & -0.4 & 0.0 & -0.6 \\
\hline$R M S E$ & 1.0 & 0.4 & 0.1 & 0.7 \\
\hline
\end{tabular}

Another part of the explanation for warmer ARPEGE temperatures over ice shelves in winter might also comes from higher latent and sensible fluxes over the sea ice area (see Fig. S5 and S4), which favours advection of warmer and 5 moist air over ice shelves. The cloudiness (not shown) and the downward longwave radiation (Fig. S6) over ice shelves being indeed higher in ARPEGE than in MAR.

Discrepancies between models for near-surface temperatures over large ice shelves and errors with respect to sparse in-

10 situ observations even for polar-oriented RCMs widely used as reference (MAR and RACMO2) shows that there is still room for improvement and that these areas might be an even more challenging test cases for surface boundary layer scheme than the high Antarctic Plateau.

\section{${ }_{15} 3$ Surface Mass Balance}

\subsection{Precipitation : comparison with MAR RCM}

In this section, the effects of driving ARPEGE with biased SSC (NorESM1-M an MIROC-ESM) on the modelling of Antarctic precipitation are evaluated trough comparisons with MAR-ERA-I total precipitation. Differences between 20 ARP-AMIP, ARP-NOR-20 and ARP-MIR-20 with MARERA-I and corresponding errors statistics for total precipitation are show in Fig. S10. Unsurprisingly, the best agreement (smaller RMSE) with MAR is found the ARP-AMIP simulation. The wet biases with respect to MAR over Dronning 25 Maud and Marie-Byrd Land evidenced in ARP-AMIP increases in both ARP-NOR-20 (Fig. S10b) and ARP-MIR-20 (Fig. S10c) simulations. The ARP-NOR-20 simulation has a systematic wet bias (larger mean error) with respect to MAR at the continent scale consistent with the $10 \%$ increase in pre- 30 cipitation rates over the grounded ice sheet with respect to ARP-AMIP in this simulation.

\subsection{Snowfall : comparisons with CloudSAT climatology}

Here, we present the comparisons of ARPEGE snowfall rates with those from the CloudSAT data set (Palerme et al., 2014, 35 2017). These results are not presented in the main part of the manuscript as they should be considered with caution for two main reasons. First, the CloudSAT data set is available for a very short period (2007-2010, and only north of $82^{\circ} \mathrm{S}$ ) which generates many uncertainties when used to evaluate a 40 

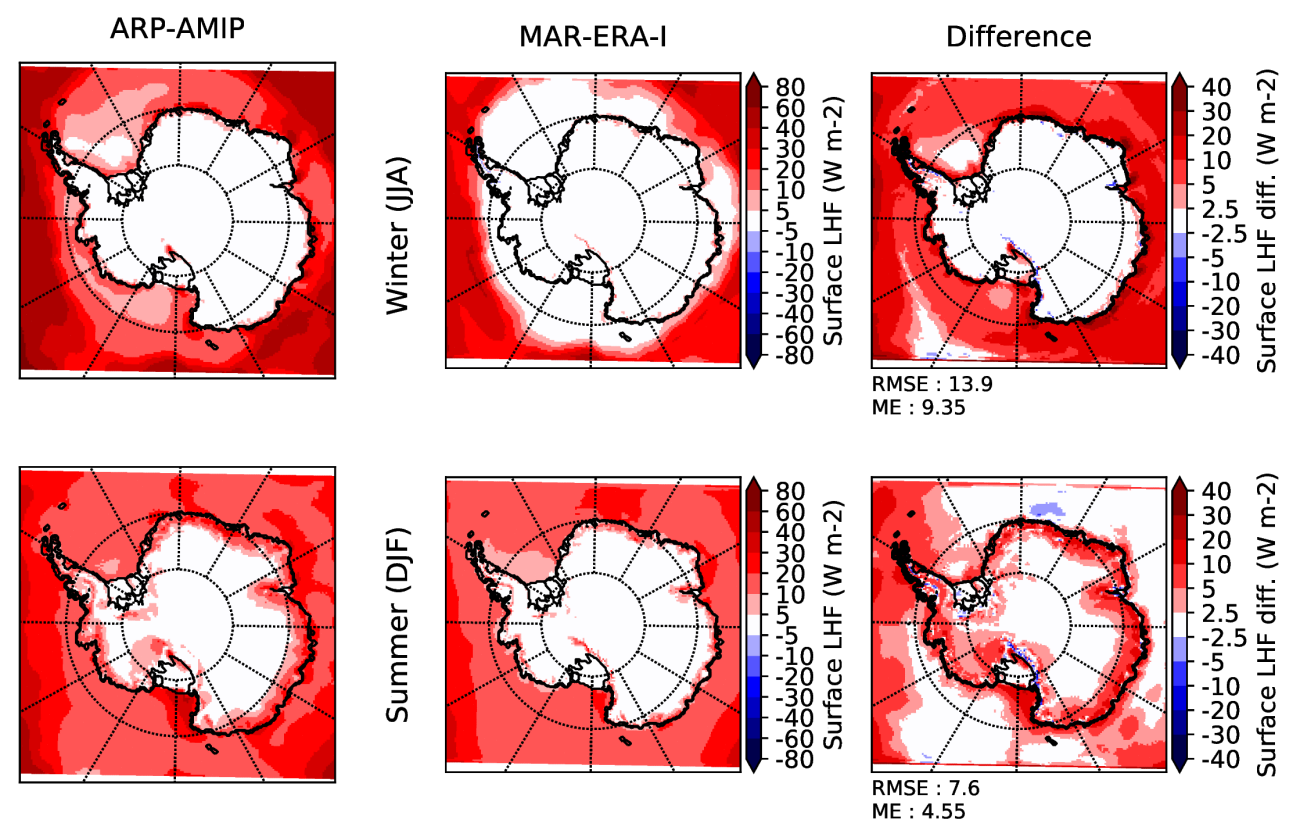

Figure S4. Mean surface latent heat flux $\left(\mathrm{W} \mathrm{m}^{-2}\right)$ in ARP-AMIP (left), MAR-ERA-I (centre) and differences between the two models (right). The 1981-2010 mean flux over winter month (JJA) are shown on the upper part of the figure, while it is shown on the lower part for summer months (DJF).
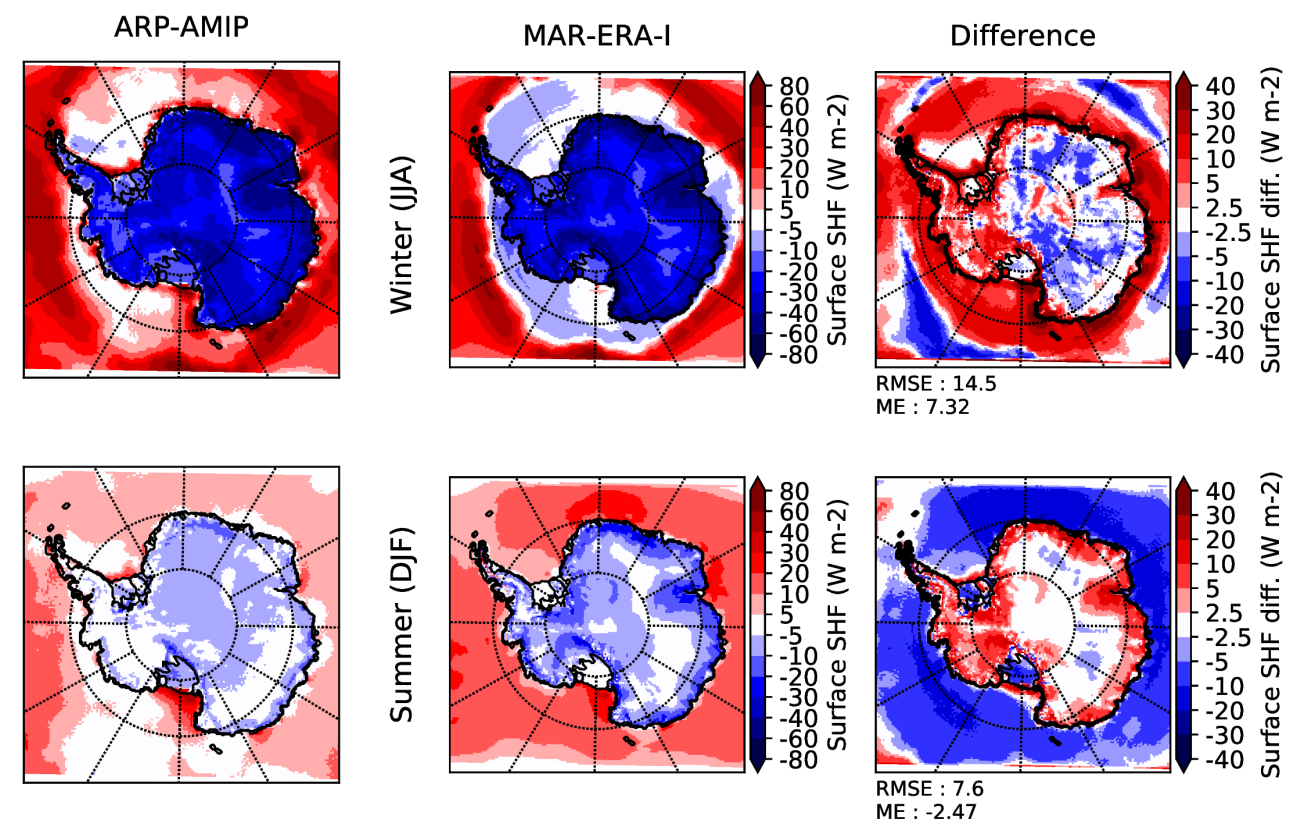

Figure S5. Same as Fig. S4 but for mean surface sensible heat flux $\left(\mathrm{W} \mathrm{m}^{-2}\right)$ 

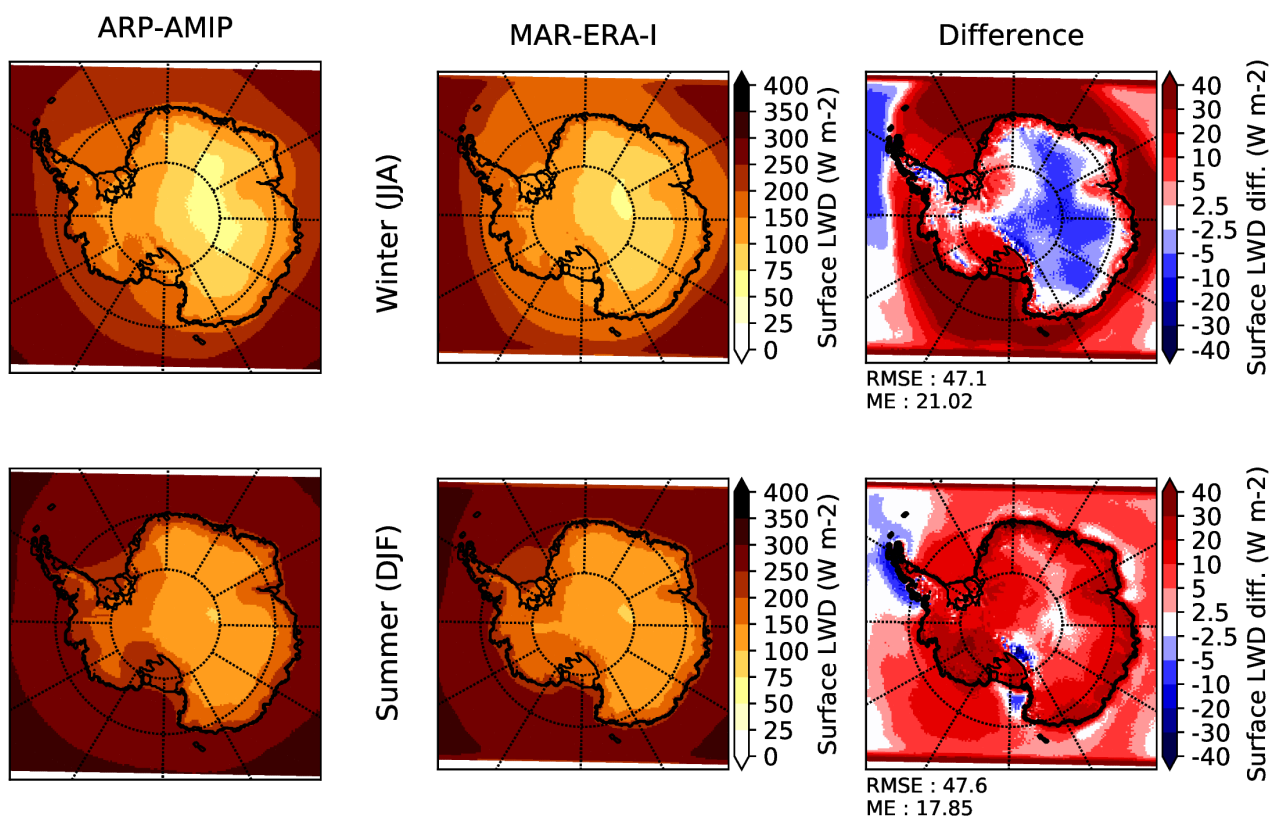

Figure S6. Same as Fig. S4 but for downward longwave radiation at the surface $\left(\mathrm{W} \mathrm{m}^{-2}\right)$.
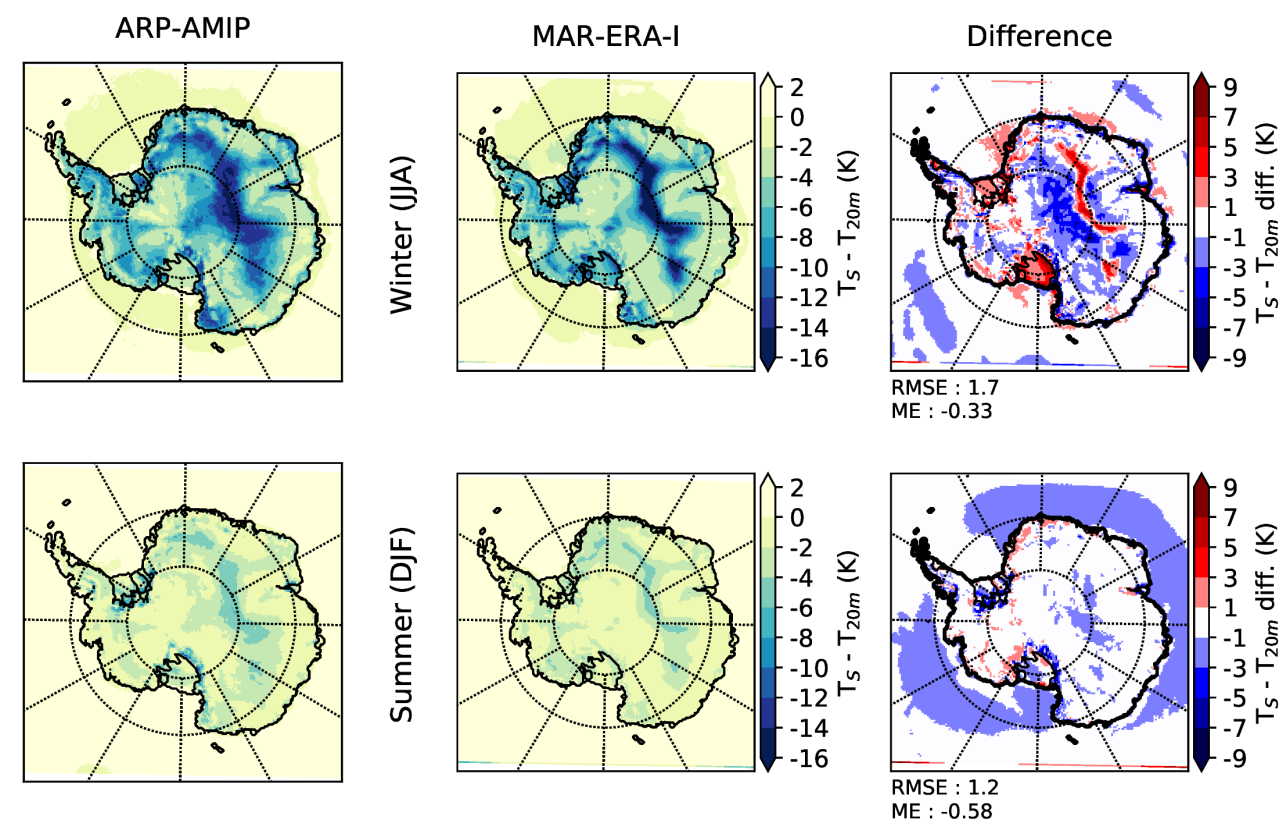

Figure S7. Near-surface temperature inversion $\left(\mathrm{T}_{\mathrm{S}}-\mathrm{T}_{20 \mathrm{~m}}\right.$, in $\mathrm{K}$ ) in ARP-AMIP (left), MAR-ERA-I (centre) and differences between the two models (right). The 1981-2010 mean for winter month (JJA) are shown on the upper part of the figure, while it is shown on the lower part for summer months (DJF). 

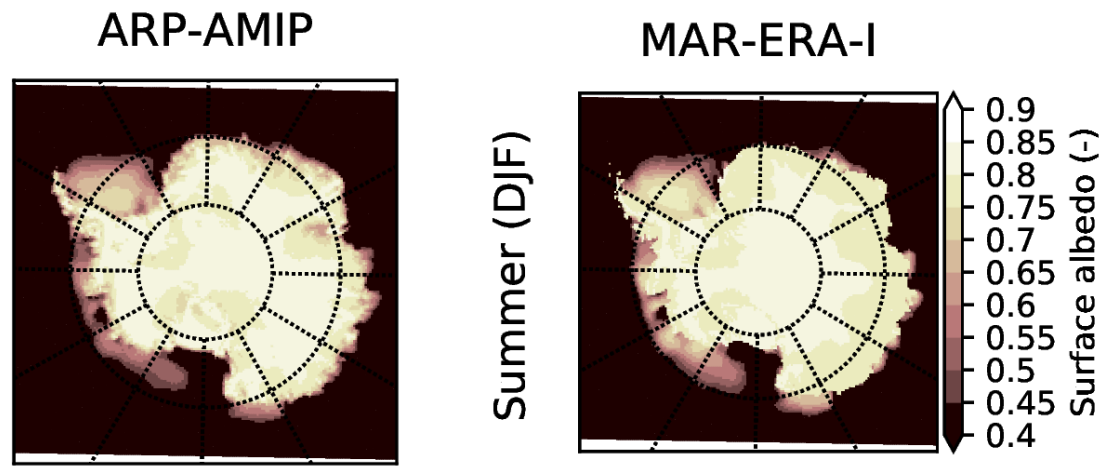

Difference

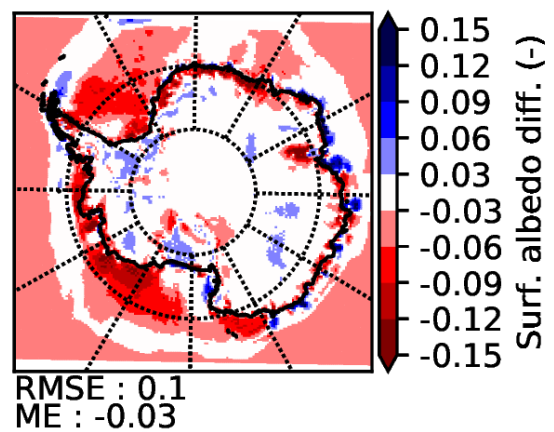

Figure S8. Mean surface summer (DJF) effective albedo (SWU/SWD) in ARP-AMIP (left), MAR-ERA-I (centre) and differences between the two models (right).

Winter Mean (JJA)

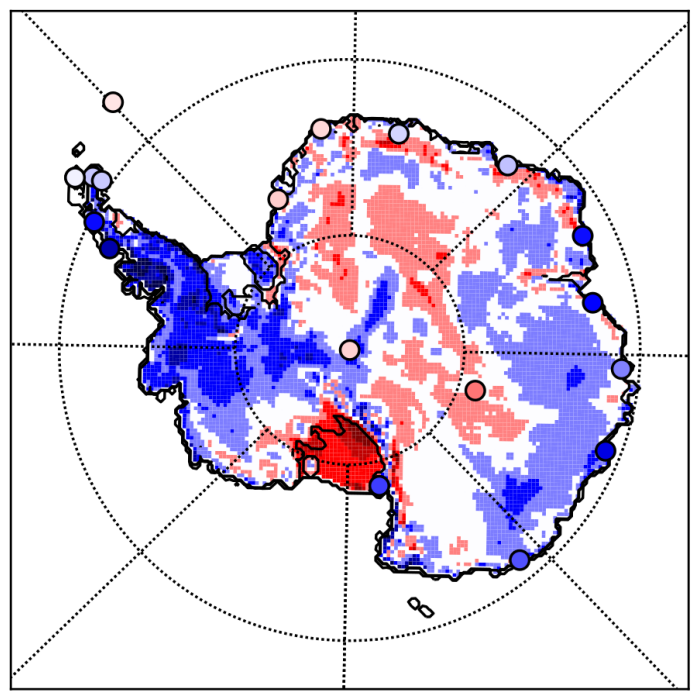

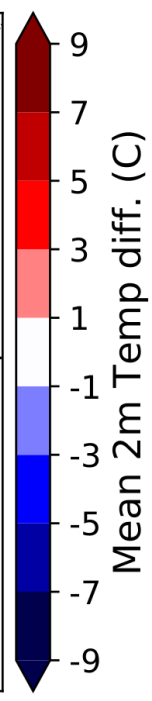

Summer Mean (DJF)

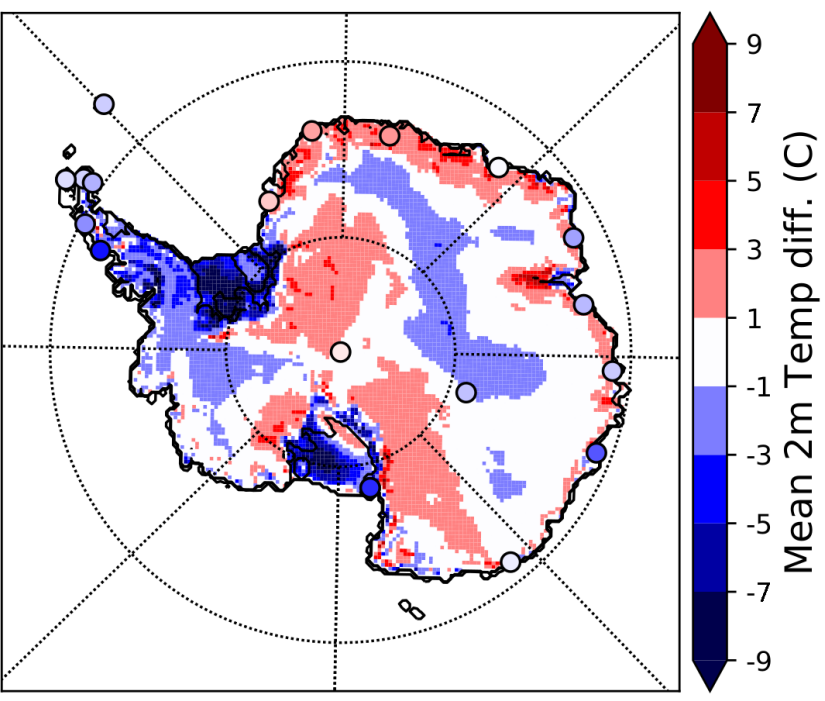

Figure S9. $\mathrm{T}_{2 m}$ differences between ARP-AMIP and ERA-I driven RACMO2 (van Wessem et al., 2018) in winter (JJA, left) and summer (DJF, right) for the reference period 1981-2010. Circles are $\mathrm{T}_{2 m}$ differences between ARP-AMIP and weather stations from the READER data base. 
a)

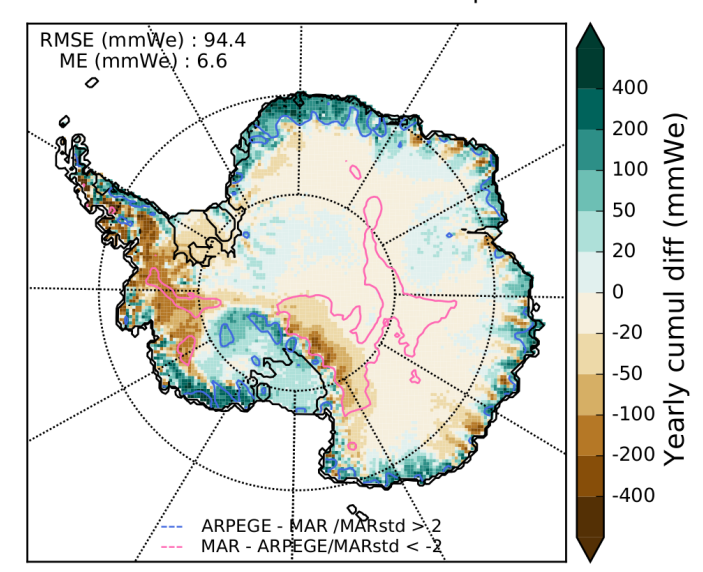

b)

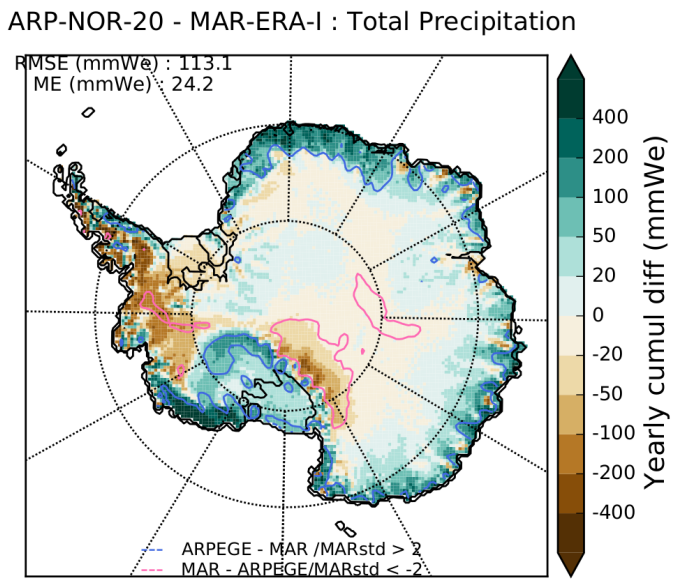

c)
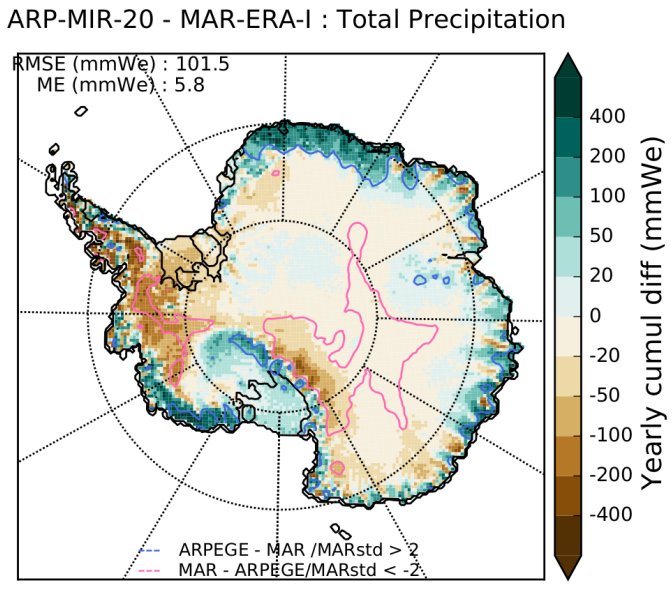

Figure S10. ARP-AMIP $(a)$, ARP-NOR-20(b) and ARP-MIR-20(c) minus MAR-ERA-I total precipitation. Pink and blue contour lines indicates where difference is larger than 2 MAR standard deviation $(2-\sigma)$. RMSE and mean error with respect to MAR are indicated in the upper-left corner. thirty years series of snowfall coming from a freely evolving climate model. Second, CloudSAT snowfall rates are representative for snowfall rates $1200 \mathrm{~m}$ above the surface as the satellite's measurements are too sensitive to ground clutter below this elevation (Palerme et al., 2014). Snowfall rates at the surface and $1200 \mathrm{~m}$ higher up can differ significantly near the ice sheet margins where the sublimation of falling snow flakes within the dry katabatic layer near the surface can be important (Grazioli et al., 2017) or over the center of the ice sheet where clear-sky precipitation forming in the lowest layers of the atmosphere represent a substantial share of yearly precipitation (Palerme et al., 2014). Snowfall rates at different elevation were not kept as default diagnostic variables when running the ARPEGE simulations presented in this study and therefore snowfall rates from CloudSAT can 1 only be compared with surface snowfall rates from ARPEGE such as done in (Palerme et al., 2017) for the comparisons with ERA-Interim reanalyses and the CMIP5 ensemble. Nevertheless, the comparison with the CloudSAT data set offers a unique opportunity to evaluate ARPEGE snowfall with a 20 reliable and model independent precipitation data set in Antartica over a wide spatial coverage.

The difference with and ratio on CloudSAT snowfall rate for the three historical ARPEGE simulations presented in this study are shown in Fig S11. The snowfall rate averaged over 25 the whole continent, the interior $(>2250 \mathrm{~m}$ a.s.l) and the peripheral $(<2250 \mathrm{~m}$ a.s.l) AIS are reported in Table S4. In this table, we also reproduced the values from ERA-I and the CMIP5 ensemble found by Palerme et al. (2017). If we consider the ARP-AMIP simulation, the overestimation of 30 the mean snowfall rate is about $30 \%$ of the CloudSAT value. ARPEGE estimate belongs to the lower half of the CMIP5 ensemble. Over the peripheral ice sheet $(<2250 \mathrm{~m})$, the overestimation in ARPEGE is about $20 \%$ of CloudSAT value. For the high interior of the AIS $(>2250 \mathrm{~m})$, the mean snowfall 35 rate in ARPEGE is almost the double of what it is in CloudSAT while ARPEGE values are close to the minimum of the CMIP5 ensemble. However, the fact that CloudSAT measurements do not account for precipitation forming below $1200 \mathrm{~m}$ above the surface suggests that snowfall in this area are less reliable and most likely underestimated (Palerme et al., 2014). The agreement between ARPEGE and ERAInterim is better in this area with overestimation in ARPEGE however still reaching about $50 \%$.

\subsection{Surface melt}

In this section, we present and briefly discuss additional results from the comparisons between ARPEGE and polaroriented RCMs MAR and RACMO2 for surface snow melt. It can be seen in Table 4 that compared to reference RCMs MAR and RACMO2 driven by ERA-I reanalyses, ARPEGE 50 represents reasonably the total integrated melt flux at the surface of the grounded AIS as the yearly mean in ARP-AMIP falls within the $\pm 1 \sigma$ range of the estimation using RACMO2 

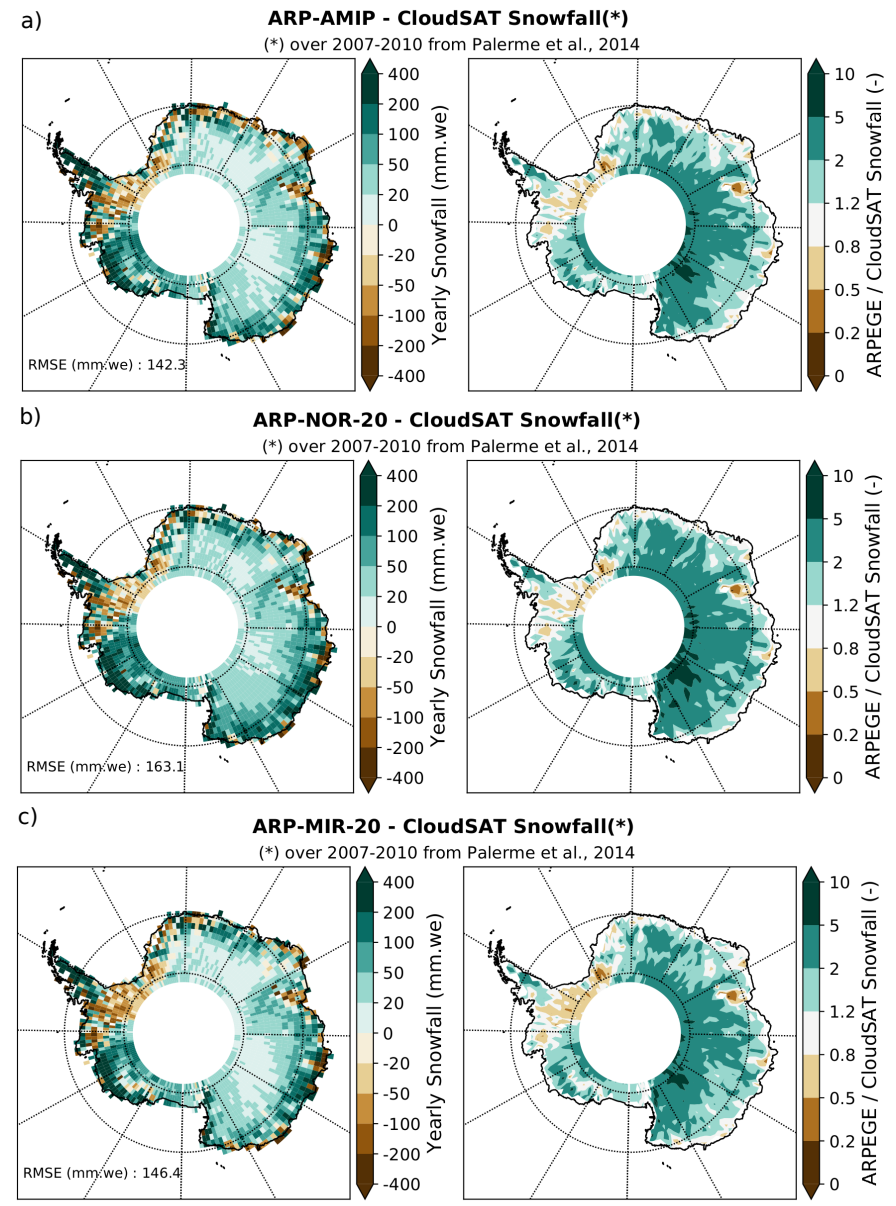

Figure S11. Left pannel : $\operatorname{ARP}-\operatorname{AMIP}(a), \operatorname{ARP}-N O R-20(b)$ and ARP-MIR-20(c) over 1981-2010 minus CloudSAT (2007-2010) yearly mean snowfall (mm.we.yr ${ }^{-1}$ ). Right pannel : ratio of ARPEGE on CloudSAT yearly mean snowfall.

Table S4. Yearly mean snowfall rate $\left(\right.$ mmwe $\left.\mathrm{yr}^{-1}\right)$ integrated north of $82^{\circ} \mathrm{S}$ over the whole continent, the interior of the AIS $(>2250$ $\mathrm{m})$ and the peripheral ice sheet $(<2250 \mathrm{~m})$ Values for ARPEGE simulations are for 1981-2010 after interpolating ARPEGE snowfall on CloudSAT $1^{\circ}$ grid. ${ }^{1}$ CloudSAT values for 2007-2010 from Palerme et al. (2017), values in parenthesis are the one found using ARPEGE land-sea mask. ${ }^{2}$ ERA-Interim, CMIP5 ensemble minimum, average and maximum values from Palerme et al. (2017) over 1986-2005.

\begin{tabular}{|c|c|c|c|}
\hline & Continent & $>2250 \mathrm{~m}$ & $<2250 \mathrm{~m}$ \\
\hline ARP-AMIP & 213 & 60 & 335 \\
\hline ARP-NOR-20 & 230 & 69 & 360 \\
\hline ARP-MIR-20 $^{2}$ & 210 & 60 & 331 \\
\hline CloudSAT $^{1}$ & $172(165)$ & $36(29)$ & $306(271)$ \\
\hline ERA-I $^{2}$ & 165 & 46 & 279 \\
\hline CMIP5 $_{\text {min }}{ }^{2}$ & 158 & 50 & 254 \\
\hline CMIP5 $_{\text {avg }}{ }^{2}$ & 224 & 74 & 363 \\
\hline CMIP5 $_{\text {max }}{ }^{2}$ & 354 & 110 & 611 \\
\hline
\end{tabular}

(Agosta et al., 2018; van Wessem et al., 2018) while the difference with MAR is $1.9 \sigma$ of MAR standard deviation. In Fig. S12a and S12b, one can see that the spatial distribution of melt areas over the AIS is reasonably represented in ARP-AMIP simulation if MAR and RACMO2 are taken as reference. In comparison with both RCMs, some limitation of ARPEGE model can however be mentioned : i) an underestimation of melt intensities over coastal areas and small ice shelves on the west and east side of the AP, consistent with ARPEGE errors on atmospheric general circulation and identified cold biases over these areas due underestimated warm and moist air advection from the north-west and possibly reduced Foëhn event frequencies on the east side of the Peninsula (Larsen Ice Shelf) ii) overestimated melt intensities over the ridge of the narrow northern part of the Peninsula likely due to poorer representation of the topography due to coarser ARPEGE horizontal resolution over this area $(\sim 45 \mathrm{kms}$ vs $35 \mathrm{kms}$ in MAR and $27 \mathrm{kms}$ in RACMO2) iii) overestimation of melt intensities over large ice shelves (RonneFilchner and Ross) consistent with reduced ARPEGE skills for the representation of surface boundary layer processes over these areas. Despite these limitations, it can be assumed that ARPEGE represents reasonably surface melt fluxes over the grounded AIS. This statement is however no longer valid if we consider run-off, as about $1 / 3$ of surface liquid water 25 inputs (rain + surface melt) leaves the snowpack in ARPEGE simulations (see Table 4), while this ratio is only 1 to $2 \%$ in MAR and RACMO2. This shows some limitations of the ISBA-ES snow scheme for the representation of the retention capacity of the Antarctic snow pack. As a result, projected 30 changes in surface run-off are not presented or discussed in section 3.2 due to limited ARPEGE skills for this variable in present climate and because of strong non-linearities often observed or predicted in changes in surface run-off in a warming climate.

\section{Atmospheric general circulation}

\subsection{Present climate}

In this section, we present supplementary material to discuss the ability of ARPEGE atmospheric model to represent the broad features of the atmospheric general circulation around 40 Antarctica. The winter (JJA) and summer (DJF) $500 \mathrm{hPa}$ geopotential heights and sea-level pressures (SLP) for ERAI reanalyses and the ARP-AMIP simulation are presented in Fig. S13. In winter, it can be seen that ARPEGE reproduces rather correctly the localization of the three climatological 45 minimum in SLP and of the maximum of the South Polar vortex, which is found above the Ross Sea rather than on the South Pole. However, as already mentioned, the depth of the three SLP minimum and the meridional pressure gradient around 50 to $60^{\circ} \mathrm{S}$ is underestimated. This remark is 50 also valid in summer. It can also be noted that ARPEGE re- 
a)
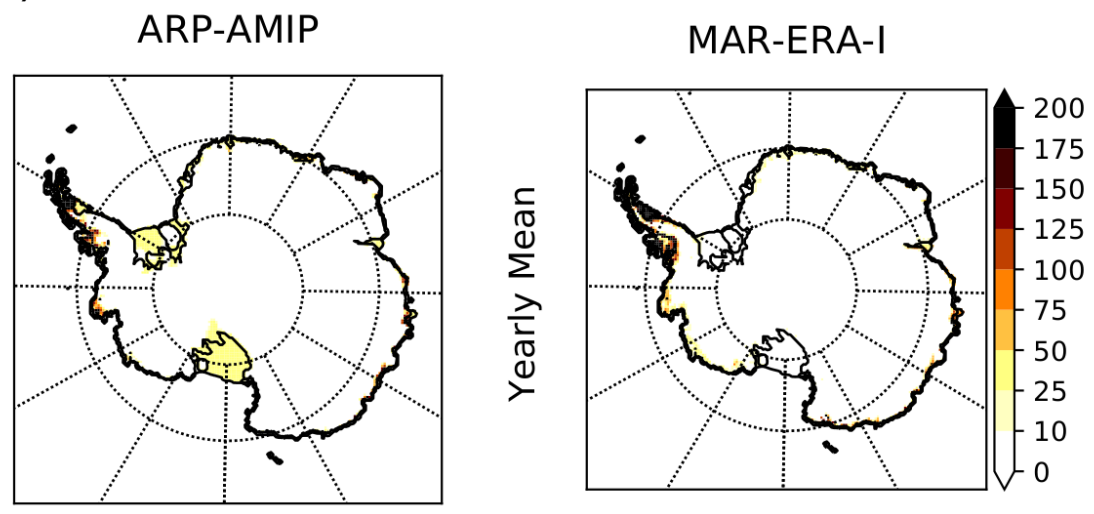

b)
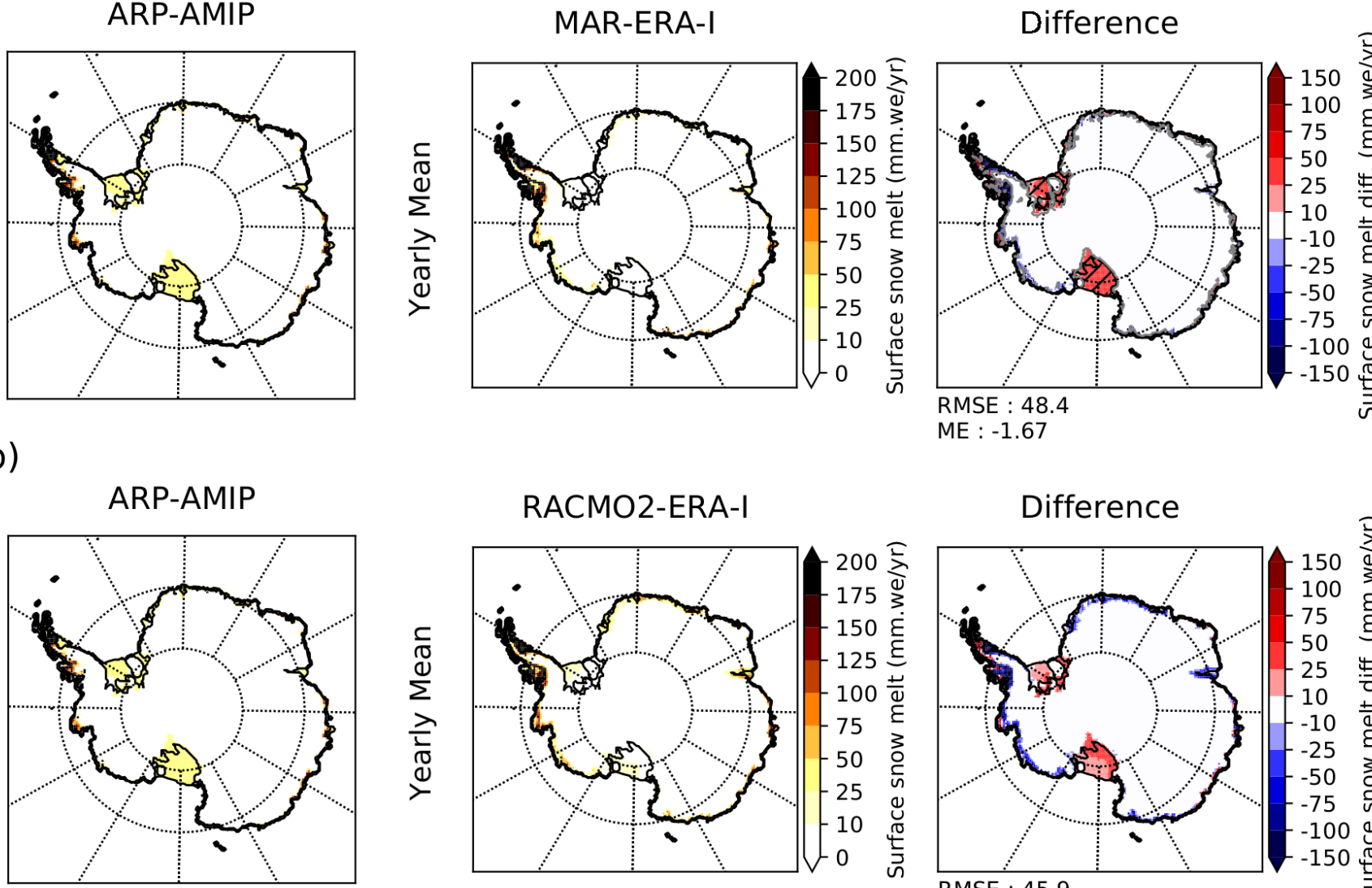

ปิ)

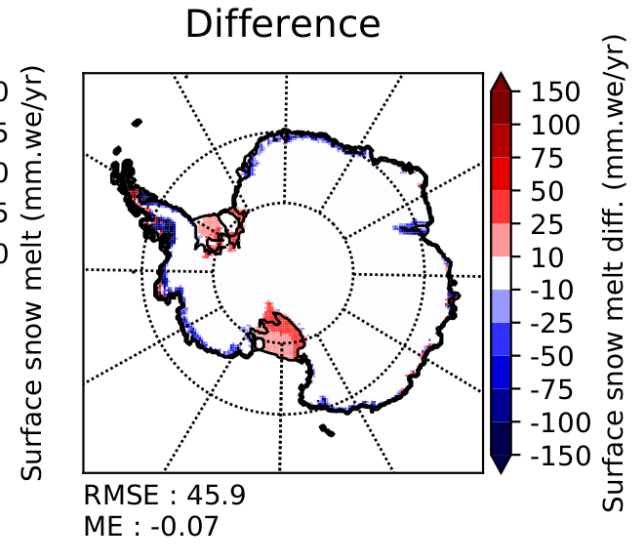

ME : -0.07

Figure S12. a) Yearly mean surface snowmelt $\left(\mathrm{mm} \cdot \mathrm{we}_{\mathrm{yr}} \mathrm{r}^{-1}\right.$ ) in ARP-AMIP (left), MAR-ERA-I (centre) and differences between the two models (right). Grey-contoured, hashed areas indicate where the difference is larger than 1 MAR standard deviation. b) : Same as a) but for the comparison with RACMO-ERA-I

produces relatively correctly the displacement of the sharper SLP minima (Amundsen Sea Low) from eastern Ross Sea in winter to the Bellingshausen Sea in summer.

\subsection{Consistency of the atmospheric model response}

${ }_{5}$ In this section, we briefly discuss the consistency of the response of the atmospheric model ARPEGE when driven by similar SSC "perturbations" between present and future climate (see Section 4.2.2). The similarities of the SSC perturbations can be appreciated in Fig. S1 and Fig. S2. The

10 consistency of the atmospheric model response is considered as being a key for having similar climate change signals between climate projections realized with or without bias-corrected SSC. In Fig. S14a, b, the difference in SLP between ARP-NOR-20 and ARP-AMIP for the four clima15 tological seasons and the corresponding difference for future climate (ARP-NOR-21-ARP-NOR-21-OC) are shown. It can be seen that there are few changes in the differences pattern between present and future climate which is to be related with the minor differences in climate changes signal found for many variables in the experiment with bias-corrected and 20 original NorESM1-M SSC. In Fig. S14c, d, the same differences for the experiment performed with MIROC-ESM SSC are displayed. Here again, the pattern of the differences are very similar. We note however a tripole in the difference for future climate (ARP-MIR-21 - ARP-MIR-21-OC) in autumn 25 (MAM), which was absent in the difference for present climate. This tripole can be related to the tripole observed for the differences in precipitation and sea-level pressure change signal observed in section 3.2.

\section{References}

Agosta, C.: Added value of the regional climate model MAR compared to reanalyses for estimating the Antarctic surface climate, 1979-2017, https://doi.org/10.5281/zenodo.1256079, https://doi. org/10.5281/zenodo.1256079, 2018. 
a) ARP-AMIP

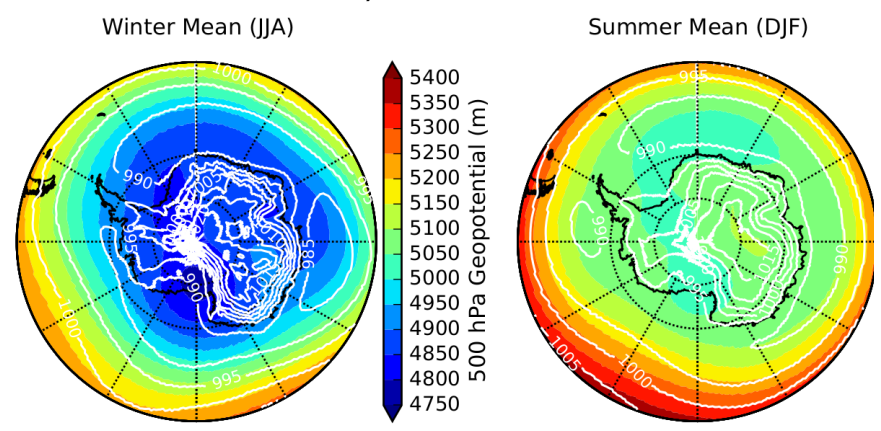

b) ERA-INT
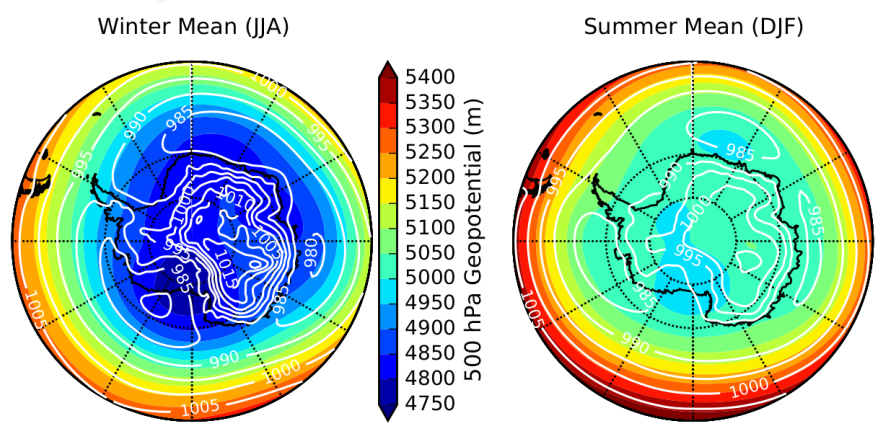

Figure S13. ERA-Interim (top) and ARP-AMIP(right) $500 \mathrm{hPa}$ geopotentials (shadings) and sea-level pressures (white contour lines) in winter (left) and summer (right) for the reference period 1981-2010.

Agosta, C., Amory, C., Kittel, C., Orsi, A., Favier, V., Gallée, H., van den Broeke, M. R., Lenaerts, J. T. M., van Wessem, J. M., and Fettweis, X.: Estimation of the Antarctic surface mass balance using MAR (1979-2015) and iden-

5 tification of dominant processes, The Cryosphere Discussions, 2018, 1-22, https://doi.org/10.5194/tc-2018-76, https://www. the-cryosphere-discuss.net/tc-2018-76/, 2018.

Bazile, E., Traullé, O., Barral, H., Le Moigne, P., Genthon, C., Guidard, V., Couvreux, F., WU, A. H., SU, G. S., and FMI, T. V.:

10 GABLS4: an intercomparison case to study the stable boundary layer with surface interactions on the Antarctic plateau., in: 21st Symposium on Boundary Layers and Turbulence, vol. 9, p. 2014, 2014.

Grazioli, J., Madeleine, J.-B., Gallée, H., Forbes, R. M., Genthon,

15 C., Krinner, G., and Berne, A.: Katabatic winds diminish precipitation contribution to the Antarctic ice mass balance, Proceedings of the National Academy of Sciences, 114, 10 858-10 863, https://doi.org/10.1073/pnas.1707633114, 2017.

King, J. C., Connolley, W. M., and Derbyshire, S. H.: Sensitivity 20 of modelled Antarctic climate to surface and boundary-layer flux parametrizations, Quarterly Journal of the Royal Meteorological Society, 127, 779-794, https://doi.org/10.1002/qj.49712757304, 2001.

Palerme, C., Kay, J., Genthon, C., L'Ecuyer, T., Wood, N., and

25 Claud, C.: How much snow falls on the Antarctic ice sheet?, The Cryosphere, 8, 1577-1587, https://doi.org/10.5194/tc-8-15772014, https://www.the-cryosphere.net/8/1577/2014/, 2014.
Palerme, C., Genthon, C., Claud, C., Kay, J. E., Wood, N. B., and L'Ecuyer, T.: Evaluation of current and projected Antarctic precipitation in CMIP5 models, Climate Dynamics, 48, 225- 30 239, https://doi.org/10.1007/s00382-016-3071-1, https://doi.org/ 10.1007/s00382-016-3071-1, 2017.

van Wessem, J. M., van de Berg, W. J., Noël, B. P. Y., van Meijgaard, E., Amory, C., Birnbaum, G., Jakobs, C. L., Krüger, K., Lenaerts, J. T. M., Lhermitte, S., Ligtenberg, S. R. M., Medley, B., Reijmer, 35 C. H., van Tricht, K., Trusel, L. D., van Ulft, L. H., Wouters, B., Wuite, J., and van den Broeke, M. R.: Modelling the climate and surface mass balance of polar ice sheets using RACMO2 Part 2: Antarctica (1979-2016), The Cryosphere, 12, 1479-1498, https://doi.org/10.5194/tc-12-1479-2018, 2018. 
a) ARP-NOR-20 - ARP-AMIP
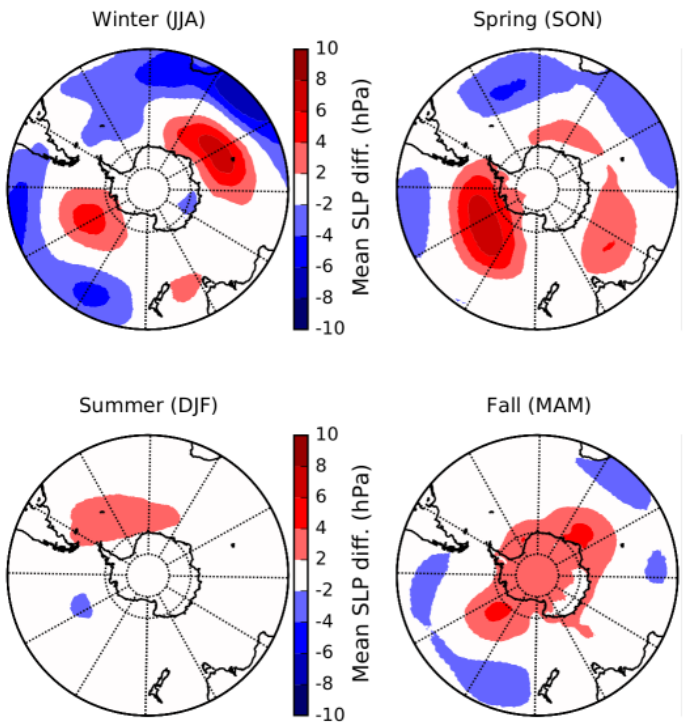

b) ARP-NOR-21 - ARP-NOR-21-OC
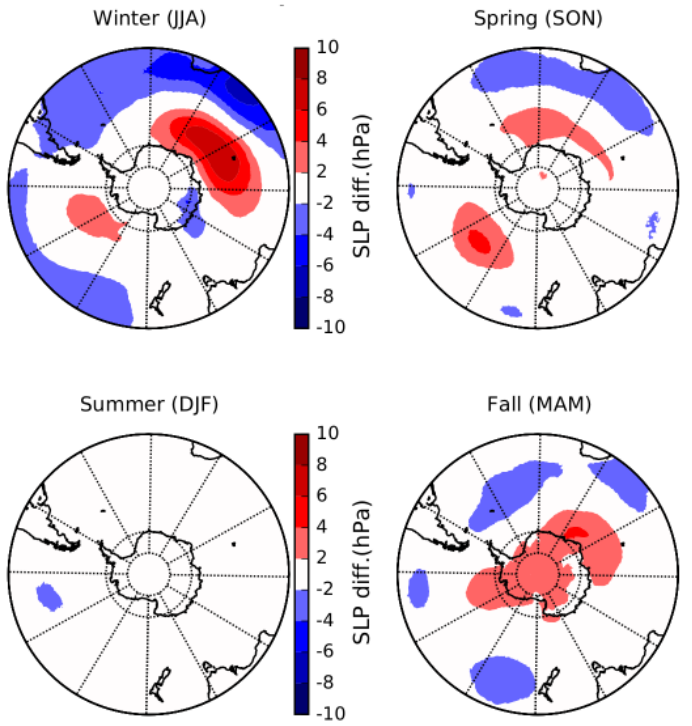

c) ARP-MIR-20 - ARP-AMIP
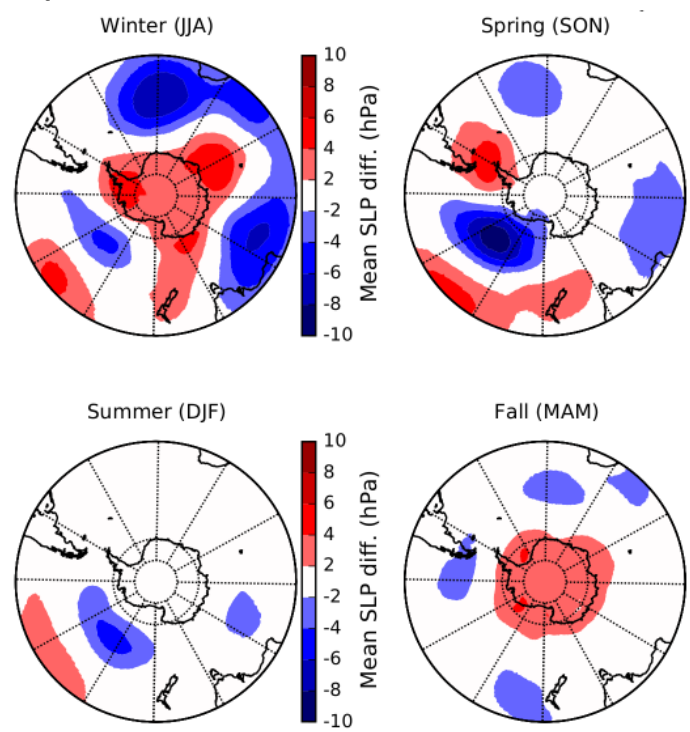

d) ARP-MIR-21 - ARP-MIR-21-OC
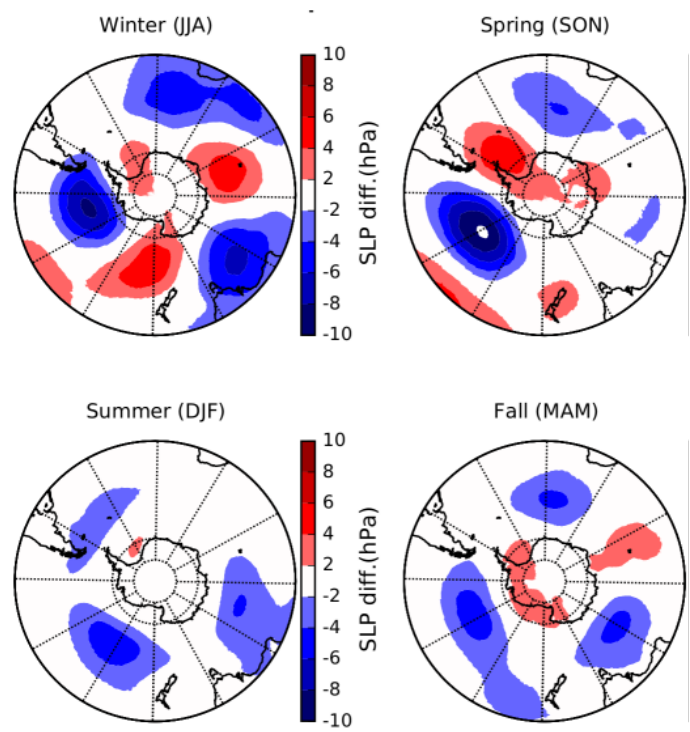

Figure S14. Difference for ARP-NOR-20 (a) and ARP-MIR-20 (b) minus ARP-AMIP for seasonal sea-level pressure (top) and corresponding differences for late $21^{\text {st }}$ century between original and bias-corrected SSC reference $(c$ and $d$ ). 